\title{
Analysis of Clinical Features and Treatment Outcomes Using 1,064-nm Nd-YAG Laser with Topical Hydroquinone in Patients with Riehl's Melanosis: A Retrospective Study in 10 Patients
}

\author{
Chong Won Choi ${ }^{1,2}$, Gwanghyun Jo ${ }^{1}$, Dong Hun Lee ${ }^{1,3}$, Seong Jin Jo ${ }^{1,3}$, Cheol Lee ${ }^{4}$, Je-Ho Mun ${ }^{1,3}$ \\ ${ }^{1}$ Department of Dermatology, Seoul National University Hospital, Seoul, ${ }^{2}$ Department of Dermatology, Seoul National University \\ Bundang Hospital, Seongnam, ${ }^{3}$ Institute of Human-Environment Interface Biology, Seoul National University, ${ }^{4}$ Department of Pathology, \\ Seoul National University College of Medicine, Seoul, Korea
}

Background: Hyperpigmentation on the face and neck can be a devastating psychological burden in patients with Riehl's melanosis. However, successful treatment of the disease is challenging for clinicians. Objective: To evaluate the effectiveness and safety of low-fluence neodymium-doped yttrium aluminum garnet ( $\mathrm{Nd}$ :YAG) laser in the treatment of Riehl's melanosis and to identify prognostic factors determining the response to laser treatment. Methods: We enrolled 10 Korean patients with Riehl's melanosis. The patients received 10 28 treatment sessions at 3-week intervals with low-fluence Nd:YAG laser. Results: Among all the patients, seven reached near total improvement, and two and one patient reached marked improvement and minimal improvement, respectively, after low-fluence Nd:YAG laser treatment. The mean number of needed laser treatment sessions to reach marked improvement and near total improvement was $12.1 \pm 4.0$ (ranged from 6 to 17 ) and $14.6 \pm 4.4$ (ranged from 9 to 20), respectively. A further analysis re-

Received December 13, 2017, Revised June 25, 2018, Accepted for publication July 23, 2018

Corresponding author: Je-Ho Mun, Department of Dermatology, Seoul National University College of Medicine, 101 Daehak-ro, Jongno-gu, Seoul 03080, Korea. Tel: 82-2-2072-2417, Fax: 82-2-742-7344, E-mail: jehomun@ gmail.com

ORCID: https://orcid.org/0000-0002-0734-2850

This is an Open Access article distributed under the terms of the Creative Commons Attribution Non-Commercial License (http://creativecommons. org/licenses/by-nc/4.0) which permits unrestricted non-commercial use, distribution, and reproduction in any medium, provided the original work is properly cited.

Copyright $\odot$ The Korean Dermatological Association and The Korean Society for Investigative Dermatology vealed the proportion of patients who reached near total improvement was higher, and the mean number of necessary laser treatment sessions to reach minimal improvement was less in patients with dark brown pigmentation compared to those with light brown pigmentation. Among all patients, three complained of guttate hypopigmentation. However, the hypopigmented lesions spontaneously improved after the interruption of the treatment. Conclusion: We found that low-fluence $\mathrm{Nd}$ :YAG laser is an effective and safe treatment modality for Riehl's melanosis. (Ann Dermatol 31(2) 127 132, 2019)

\section{-Keywords-}

Melanosis, Nd-YAG laser, Pigmentation, Riehl's melanosis, Therapeutics

\section{INTRODUCTION}

Riehl's melanosis is a form of contact dermatitis that is characterized by a brown to gray pigmentation over the face $^{1}$. Although the pathogenesis of Riehl's melanosis remains largely unknown, recent studies suggest that Riehl's melanosis is associated with Riehl's melanosis caused by ingredients of cosmetics ${ }^{1,2}$. Facial pigmentation can be a devastating psychological burden in patients with this condition. However, conventional treatments are often unsatisfactory. The mainstay of treatment of Riehl's melanosis is as follows: avoidance of identified contact allergens, sun protection, and topical application of bleaching agents. 
Favorable results using low-fluence Q-switched neodymiumdoped yttrium aluminum garnet ( $\mathrm{Nd}: \mathrm{YAG}$ ) laser in the treatment of facial pigmentary disorders, including melasma, nevus of Ota, and postinflammatory hyperpigmentation, have been reported ${ }^{3-7}$. Although the specific mechanism of low-fluence $\mathrm{Nd}$ :YAG laser for pigmentary disorders was unknown, ultrastructural changes in melanosomes were found after irradiation with low-fluence $\mathrm{Nd}$ :YAG laser ${ }^{8}$. Recently, studies have reported the use of low-fluence $\mathrm{Nd}$ :YAG laser in the treatment of Riehl's melanosis ${ }^{2,9}$.

In this study, we investigated 10 patients with clinicopathologically confirmed Riehl's melanosis and assessed the effectiveness of low-fluence $\mathrm{Nd}$ :YAG laser in the treatment of the disease. In addition, we analyzed clinical parameters in terms of treatment response to low-fluence $\mathrm{Nd}$ :YAG laser to identify prognostic factors in treating Riehl's melanosis.

\section{MATERIALS AND METHODS}

Ten patients with Riehl's melanosis were enrolled in this study. The patients visited Seoul National University Hospital (SNUH) for the management of hyperpigmentation of their facial region. The diagnosis of Riehl's melanosis was established based on clinical and histopathologic analyses of patients. To distinguish from simple postinflammatory hyperpigmentation, the absence or presence of preceding symptoms for overt inflammation at the site of pigmentation was thoroughly investigated. Skin biopsies were performed to rule out other pigmentary disorders such as melasma, nevus of Ota, acquired bilateral nevus of Ota-like macules, and ochronosis. To screen possible causative allergens, a patch test was performed in all except three patients. After confirming the causative allergens, the patients were educated to avoid the use of any cosmetics that contained the causative allergens.

To treat Riehl's melanosis, the patients received a treatment using a 1,064-nm Q-switched Nd:YAG laser (Pastelle ${ }^{\circledR}$; WONTECH, Seoul, Korea) at a three-week interval. The parameters of the laser treatment were as follows: fluence started from $0.9 \mathrm{~J} / \mathrm{cm}^{2}$ with a $7-\mathrm{mm}$-sized spot and frequency of $10 \mathrm{~Hz}$. The fluence of the laser was adjusted up to $2.0 \mathrm{~J} / \mathrm{cm}^{2}$ based on the patient's sensitivity to pain and response to the previous treatment. The laser treatment was applied to the pigmented lesion with appropriate overlap and repeated with three to four passes until the pigmented lesions showed subtle erythema without petechiae. Each treatment session took about 20 minutes. At each visit before the treatment session, we asked the patient about the degree of improvement and the develop- ment of adverse events and took standardized clinical photographs under the same lighting condition using a digital camera (550D; Canon, Tokyo, Japan) to record the progress. In addition, the degree of improvement and the development of adverse events were further confirmed by using wood light. The additional session of laser treatment was determined by the patient's response to previous treatments, satisfaction, and need for further treatment. During the laser treatment, $4 \%$ hydroquinone cream (Eldoquin Forte ${ }^{R}$; ICN Pharmaceuticals Inc., Costa Mesa, CA, USA) was concurrently used on the hyperpigmented lesions in eight patients.

Objective assessments of improvement were performed by two investigators using standardized photographs taken before each treatment session. They compared the standardized photographs with the pretreatment photographs and evaluated the improvement of each treatment session based on the following grading scale $(1 \sim 5)$ : grade 0 (worsening or stable disease), grade 1 (minimal improvement, $0 \%$ $25 \%$ improvement), grade 2 (moderate improvement, $26 \%$ $50 \%$ improvement), grade 3 (marked improvement, 51\% $75 \%$ improvement), and grade 4 (near total improvement, more than $75 \%$ improvement).

The effectiveness of low-fluence Q-switched Nd:YAG laser in the treatment of Riehl's melanosis was investigated by evaluating the grade of improvement and number of treatment sessions required to achieve each grade of improvement. To identify the prognostic factors in the treatment of Riehl's melanosis, we compared the improvement grade and number of treatment sessions required for improvement according to the clinical characteristics or demographic factors, using the Mann-Whitney $U$ and Fisher's exact tests. SPSS 22.0 (IBM Co., Armonk, NY, USA) was used to perform statistical analysis. Data are shown as a mean \pm standard deviation. A $p$-value of $<0.05$ was considered statistically significant.

This study was approved by the Institutional Review Board of SNUH (IRB no. H-1705-097-856). We received the patient's consent form about publishing all photographic materials.

\section{RESULTS}

The demographic data and clinical information of the 10 patients are summarized in Table 1. All patients were females of Korean descent, and the mean age of the enrolled patients was $60.3 \pm 11.9$ years (ranged from 46 to 81 years). All patients had pigmented lesions on their face and nine patients on their neck. Before the development of pigmented lesions, seven patients experienced symptoms of mild itching or erythema. The color of the pig- 
Table 1. Summary of patients' characteristics

\begin{tabular}{|c|c|c|c|c|c|c|c|}
\hline $\begin{array}{l}\text { Patient } \\
\text { no. }\end{array}$ & $\begin{array}{l}\text { Age } \\
(y r)\end{array}$ & $\begin{array}{l}\text { Disease } \\
\text { duration } \\
\quad(\mathrm{mo})\end{array}$ & Symptoms & Involvement & $\begin{array}{c}\text { Color of } \\
\text { pigmentation }\end{array}$ & $\begin{array}{l}\text { Pattern of } \\
\text { pigmentation }\end{array}$ & Results of patch test \\
\hline 1 & 69 & 36 & None & Face and neck & Light brown & Reticulate & Benzyl salicylate $(+)$ \\
\hline 2 & 55 & 48 & Itching & Face and neck & Light brown & Homogenous & Not performed \\
\hline 3 & 71 & 120 & None & Face and neck & Light brown & Reticulate & $\begin{array}{l}\text { Cobalt chloride }(2+), \text { 1, 2-dibromo-2, } \\
\text { 4-dicyanobutane }(+) \\
\text { As is }(2+: \text { shampoo })\end{array}$ \\
\hline 4 & 53 & 24 & Itching & Face and neck & Light brown & Homogenous & Nickel sulfate $(2+)$, cobalt chloride $(+)$ \\
\hline 5 & 70 & 18 & None & Face and neck & Dark brown & Homogenous & No positive test results \\
\hline 6 & 61 & 12 & $\begin{array}{l}\text { Itching, } \\
\text { erythema }\end{array}$ & Face & Dark brown & Reticulate & $\begin{array}{l}\text { Carba mix }(+) \text {, benzyl salicylate }(+) \\
2(2-\text { Hydroxy-5-methylphenyl)benzotriazole } \\
(\text { Tinuvin } P)(2+)\end{array}$ \\
\hline 7 & 46 & 6 & Itching & Face and neck & Dark brown & Homogenous & Balsam of Peru $(2+)$ \\
\hline 8 & 50 & 1 & $\begin{array}{l}\text { Itching, } \\
\text { erythema }\end{array}$ & Face and neck & Dark brown & Reticulate & Not performed \\
\hline 9 & 81 & 6 & Itching & Face and neck & Dark brown & Homogenous & Not performed \\
\hline 10 & 47 & 24 & Itching & Face and neck & Dark brown & Homogenous & $\begin{array}{l}\text { Potassium dichromate }(+) \text {, cobalt chloride }(+) \\
\text { As is }(+: \text { shampoo })\end{array}$ \\
\hline
\end{tabular}

Table 2. Summary of the responses and side effects to low-fluence Q-switched Nd:YAG laser treatment

\begin{tabular}{|c|c|c|c|c|c|c|}
\hline Patient no. & $\begin{array}{c}\text { Total number of } \\
\text { treatment } \\
\text { sessions }\end{array}$ & $\begin{array}{l}\text { Session for } \\
\text { grade } 1 \\
\text { improvement }\end{array}$ & $\begin{array}{l}\text { Session for } \\
\text { grade } 2 \\
\text { improvement }\end{array}$ & $\begin{array}{l}\text { Session for } \\
\text { grade } 3 \\
\text { improvement }\end{array}$ & $\begin{array}{l}\text { Session for } \\
\text { grade } 4 \\
\text { improvement }\end{array}$ & Adverse events \\
\hline 1 & 18 & 5 & 9 & 12 & 16 & None \\
\hline 2 & 20 & 6 & 12 & 17 & Not reached & Guttate hypopigmentation \\
\hline 3 & 19 & 11 & 15 & 17 & Not reached & Guttate hypopigmentation \\
\hline 4 & 10 & 7 & Not reached & Not reached & Not reached & None \\
\hline 5 & 28 & 4 & 10 & 14 & 19 & None \\
\hline 6 & 20 & 3 & 5 & 9 & 13 & None \\
\hline 7 & 22 & 2 & 7 & 11 & 16 & $\begin{array}{l}\text { Transient aggravation after } \\
\text { treatment }\end{array}$ \\
\hline 8 & 21 & 2 & 12 & 15 & 20 & $\begin{array}{l}\text { Transient aggravation after } \\
\text { treatment }\end{array}$ \\
\hline 9 & 11 & 3 & 5 & 8 & 9 & None \\
\hline 10 & 10 & 2 & 4 & 6 & 9 & Guttate hypopigmentation \\
\hline Mean \pm SD & $17.9 \pm 5.9$ & $4.5 \pm 2.9$ & $8.8 \pm 3.8$ & $12.1 \pm 4.0$ & $14.6 \pm 4.4$ & \\
\hline
\end{tabular}

SD: standard deviation.

mented lesion was dark brown in six patients and light brown in the remaining four patients. The pattern of pigmentation was homogenous in six and reticulated in four patients. The histopathologic findings included a variable degree of pigmentary incontinence, lymphocytic infiltration in the upper dermis, and focal basal vacuolar alteration of the epidermis in all patients.

The response to low-fluence Q-switched Nd:YAG laser treatment is summarized in Table 2. The mean number of performed treatment was $17.9 \pm 5.9$ (ranged from 10 to 28). All but one patient achieved grade 3 improvement. Specifically, seven patients reached grade 4 while two pa- tients showed grade 3 improvement. However, one patient failed to reach grade 2 improvement even after 10 sessions of treatment. The mean number of laser treatment sessions to reach grade $1,2,3$, and 4 improvement was $4.5 \pm 2.9$ (range, $2 \sim 11), 8.8 \pm 3.8(4 \sim 15), 12.1 \pm 4.0$ (6 $17)$, and $14.6 \pm 4.4(9 \sim 20)$, respectively. Among the patients, three complained of guttate hypopigmentation; however, the hypopigmented lesions spontaneously improved after interruption of the laser treatment at the site of hypopigmentation. In addition, two patients experienced a transient aggravation of pigmentation after laser treatment. However, lowering the fluence improved the ag- 
gravated pigmentation.

To identify prognostic factors determining the treatment response for Riehl's melanosis, we compared the results of laser treatment according to the clinical characteristics or demographic factors. We found that the color of pigmentation can be a determining factor for the response to the treatment: patients with dark brown hyperpigmentation showed more favorable responses than those with light brown hyperpigmentation (Fig. 1). The subgroup analysis between the groups revealed the proportion of patients who reached grade 4 improvement was higher $(100 \%$ in dark brown and $25 \%$ in light brown, $p$-value $=0.03$ ) and the mean needed numbers of laser treatment sessions to reach grade 1 improvement were less in patients with dark brown pigmentation $(2.7 \pm 0.8$ in dark brown and $7.3 \pm 2.6$ in light brown, $p$-value $=0.01$ ) (Table 3 ). In our data, the disease duration was shorter in patients with dark brown pigmentation (11.2 \pm 8.6 months) than in those with light brown pigmentation $(57.0 \pm 43.1$ months). Therefore, we performed a subgroup analysis on the effect of disease duration in comparing the outcome measures of patients who have had the disease for less than or more than 12 and 24 months, respectively. Results showed no statistically significant association between disease duration and treatment outcome (data not shown). We could not find a significant association in other variables such as age, total number of treatment sessions, and the proportion of patients experiencing symptoms or adverse events.
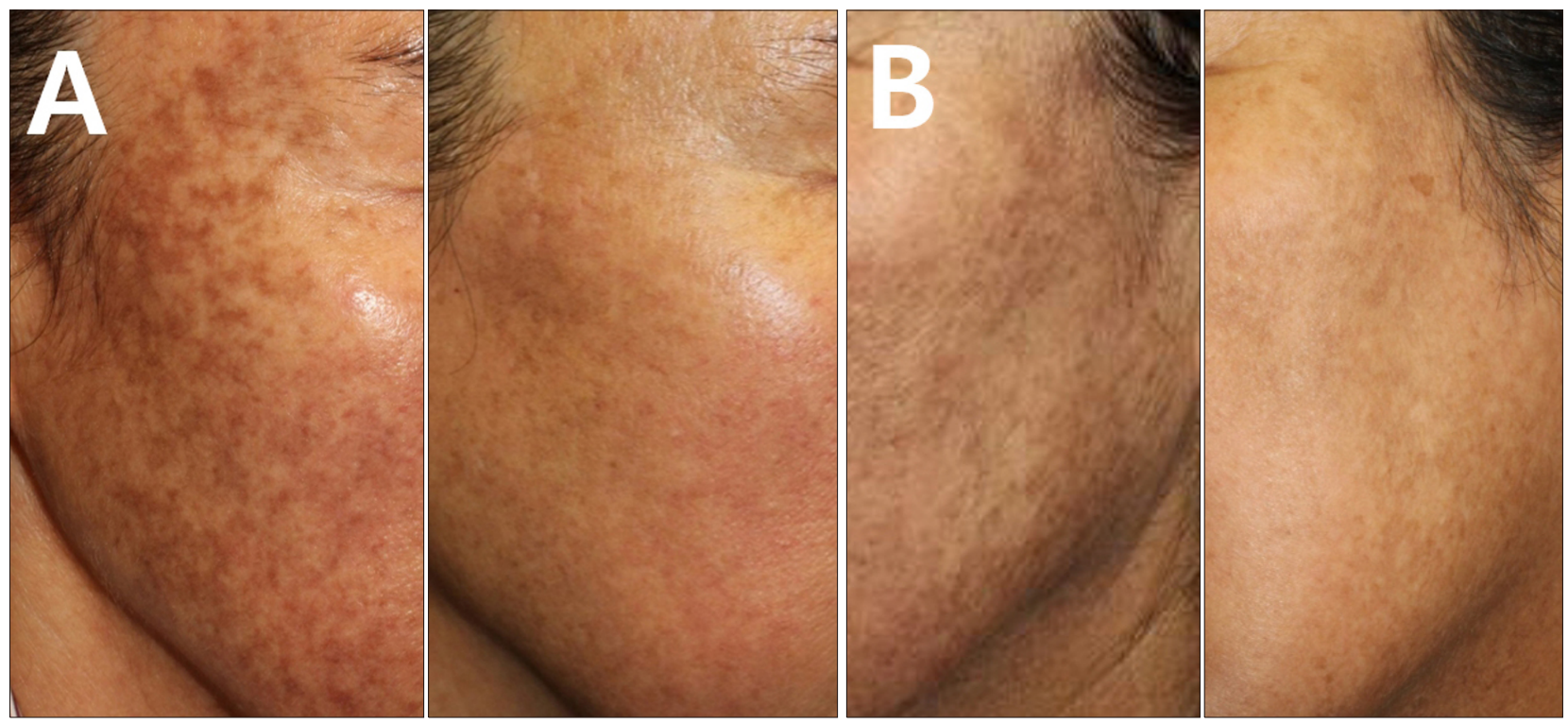

Fig. 1. Representative photographs of a patient with Riehl's melanosis showing dark brown hyperpigmentation and light brown hyperpigmentation. Representative photographs of a patient with Riehl's melanosis showing dark brown hyperpigmentation at baseline and after reaching grade 4 improvement (more than 75\% improvement) with 19 treatment sessions of low-fluence Q-switched Nd:YAG laser (A). Representative photographs of light brown hyperpigmentation at baseline and after reaching grade 4 improvement (more than $75 \%$ improvement) with the 17 treatment sessions of low-fluence Q-switched Nd:YAG laser (B).

Table 3. A comparison of the response to treatment between patients with dark brown and light brown hyperpigmentation

\begin{tabular}{|c|c|c|c|}
\hline Characteristic & $\begin{array}{c}\text { Dark brown } \\
\text { hyperpigmentation }\end{array}$ & $\begin{array}{l}\text { Light brown } \\
\text { hyperpigmentation }\end{array}$ & $p$-value \\
\hline Number of patients & 6 & 4 & \\
\hline Disease duration (mo) & $11.2 \pm 8.6$ & $57.0 \pm 43.1$ & 0.01 \\
\hline Number of patients who reached grade 3 improvement & $6(100)$ & $3(75)$ & 0.40 \\
\hline Number of patients who reached grade 4 improvement & $6(100)$ & $1(25)$ & 0.03 \\
\hline Treatment sessions for grade 1 improvement & $2.7 \pm 0.8(2 \sim 4)$ & $7.3 \pm 2.6(5 \sim 11)$ & 0.01 \\
\hline Treatment sessions for grade 2 improvement & $7.2 \pm 3.2(4 \sim 12)$ & $12.0 \pm 3.0(9 \sim 15)$ & 0.10 \\
\hline Treatment sessions for grade 3 improvement & $10.5 \pm 3.5(6 \sim 15)$ & $15.3 \pm 2.9(12 \sim 17)$ & 0.10 \\
\hline Treatment sessions for grade 4 improvement & $14.3 \pm 4.8(9 \sim 20)$ & 16 & 0.86 \\
\hline
\end{tabular}

Values are presented as number only, mean \pm standard deviation, number $(\%)$, or mean \pm standard deviation (range). 


\section{DISCUSSION}

The pathophysiology of pigmentations in Riehl's melanosis remains unknown. Previous studies suggested that Riehl's melanosis is a form of pigmentary disorder caused by ingredients of cosmetics ${ }^{10}$. In our study, seven patients underwent patch tests, and six patients (85.7\%) showed positive response to at least one allergen (Table 1 ). Considering that the pigmentation of Riehl's melanosis is caused by inflammation ${ }^{10}$, it can be inferred that the treatment modalities used for postinflammatory hyperpigmentation will be also useful for Riehl's melanosis. Recent studies have shown that low-fluence 1,064-nm Nd:YAG laser treatment is effective for postinflammatory hyperpigmentation $^{5,11}$. Therefore, we attempted low-fluence 1,064-nm $\mathrm{Nd}$ :YAG laser treatment for Riehl's melanosis. In the present study, we found that low-fluence $\mathrm{Nd}$ :YAG laser treatment for Riehl's melanosis showed satisfactory results with a steady improvement: $90.0 \%$ of patients showed grade 2 improvement and $70.0 \%$ achieved grade 4 improvement. Since Riehl's melanosis is thought to be a form of postinflammatory hyperpigmentation ${ }^{1,2}$, treatments with a strong stimulus can exacerbate the preexisting pigmentation. In the present study, we experienced cases of exacerbation of existing pigmentation in two patients, although we used a laser modality with low energy. However, the rebound hyperpigmentation improved after additional low-fluence $\mathrm{Nd}$ :YAG laser treatment with the parameters adjusted. Based on our results, we suggest that low-fluence $\mathrm{Nd}$ :YAG laser can be a suitable treatment for Riehl's melanosis.

Since the wide use of the low-fluence $\mathrm{Nd}$ :YAG laser for pigmentary lesions, there have been increasing reports of potential adverse events after the treatment. Among them, a mottled hypopigmentation after multiple sessions of low-fluence Nd:YAG laser treatment has been reported. ${ }^{2,12}$ Previous studies suggested that mottled hypopigmentation was caused by the impairment of melanogenesis rather than apoptosis of melanocytes ${ }^{12,13}$. Because there is no established treatment for mottled hypopigmentation and it can cause serious emotional distress to patients, it is necessary to detect it at an early stage and prevent its progression. In this study, to prevent the development of mottled hypopigmentation, the patient was treated in an interval of at least three weeks. Moreover, we used wood light to identify the development of hypopigmentation at each visit. In this study, three patients experienced the development of guttate hypopigmentation. However, because of the early interruption of the laser treatment at the site of hypopigmentation, further pigmentary change was prevented. Eventually, the hypopigmentation improved on its own.
In this study, we further analyzed factors affecting the response to low-fluence $\mathrm{Nd}$ :YAG laser treatment and found that patients with dark brown hyperpigmentation showed more favorable responses than those with light brown hyperpigmentation. The proportion of patients who reached near total improvement was higher and the response to low-fluence Nd:YAG laser treatment was quicker in patients with dark brown hyperpigmentation. Specifically, our data showed that significant difference in the proportion of patients and the mean number of laser treatment sessions for grade 1 and 4 exist between light brown and dark brown pigmentation. The results can be meaningful because grade 1 is the first notable treatment improvement and grade 4 represents a significant improvement. In addition, although statistically nonsignificant, the number of treatment sessions for moderate and marked improvement was less in patients with dark brown hyperpigmentation. We assumed the amount of melanin pigment in dark brown hyperpigmentation can be more abundant, and the response may be conspicuous during the same treatment. Furthermore, considering that the color of pigmentation is related to the position of the pigment in the skin along with the amount of melanin pigment ${ }^{14}$, the difference in response to the treatment may be associated with the location as well as the amount of the melanin pigment in Riehl's melanosis. Additionally, although analysis of our data did not determine a statistically significant effect of disease duration on the treatment outcome, a further study with large samples is necessary to exclude any confounding effects of disease duration.

In conclusion, we found that low-fluence $\mathrm{Nd}$ :YAG laser is an effective and safe treatment modality for Riehl's melanosis. Multiple sessions of low-fluence $\mathrm{Nd}$ :YAG laser treatment resulted in marked or near total improvement in the majority of patients. However, it should be noted that adverse effects, such as temporary aggravation or mottled hypopigmentation, can occur, although they can be managed successfully. A further prospective study with a large number of enrolled subjects is necessary to validate the results of our study.

\section{CONFLICTS OF INTEREST}

The authors have nothing to disclose.

\section{ORCID}

Chong Won Choi, https://orcid.org/0000-0001-9994-8819

Gwanghyun Jo, https://orcid.org/0000-0003-0580-2312

Dong Hun Lee, https://orcid.org/0000-0002-2925-3074

Seong Jin Jo, https://orcid.org/0000-0002-2501-7672 
Cheol Lee, https://orcid.org/0000-0001-5098-8529

Je-Ho Mun, https://orcid.org/0000-0002-0734-2850

\section{REFERENCES}

1. Serrano G, Pujol C, Cuadra J, Gallo S, Aliaga A. Riehl's melanosis: pigmented contact dermatitis caused by fragrances. J Am Acad Dermatol 1989;21:1057-1060.

2. Chung BY, Kim JE, Ko JY, Chang SE. A pilot study of a novel dual--pulsed $1064 \mathrm{~nm}$ Q-switched Nd: YAG laser to treat Riehl's melanosis. J Cosmet Laser Ther 2014;16:290-292.

3. Choi CW, Kim HJ, Lee HJ, Kim YH, Kim WS. Treatment of nevus of Ota using low fluence Q-switched $\mathrm{Nd}$ :YAG laser. Int J Dermatol 2014;53:861-865.

4. Jeong SY, Shin JB, Yeo UC, Kim WS, Kim IH. Low-fluence Q-switched neodymium-doped yttrium aluminum garnet laser for melasma with pre- or post-treatment triple combination cream. Dermatol Surg 2010;36:909-918.

5. Kim S, Cho KH. Treatment of procedure-related postinflammatory hyperpigmentation using 1064-nm Q-switched Nd:YAG laser with low fluence in Asian patients: report of five cases. J Cosmet Dermatol 2010;9:302-306.

6. Nam JH, Kim HS, Lee GY, Kim WS. Beneficial effect of low fluence 1,064 nm Q-Switched Neodymium: Yttrium-AluminumGarnet laser in the treatment of senile lentigo. Ann Dermatol 2017;29:427-432.

7. Nam JH, Kim HS, Choi YJ, Jung HJ, Kim WS. Treatment and classification of nevus of ota: a seven-year review of a single institution's experience. Ann Dermatol 2017;29:446-453.

8. Mun JY, Jeong SY, Kim JH, Han SS, Kim IH. A low fluence Q-switched Nd:YAG laser modifies the 3D structure of melanocyte and ultrastructure of melanosome by subcellularselective photothermolysis. J Electron Microsc (Tokyo) 2011; 60:11-18.

9. Kwon HH, Ohn J, Suh DH, Park HY, Choi SC, Jung JY, et al. A pilot study for triple combination therapy with a lowfluence 1064 nm Q-switched Nd:YAG laser, hydroquinone cream and oral tranexamic acid for recalcitrant Riehl's Melanosis. J Dermatolog Treat 2017;28:155-159.

10. Sugai $T$, Takahashi $Y$, Takagi T. Pigmented cosmetic dermatitis and coal tar dyes. Contact Dermatitis 1977;3:249-256.

11. Kim S, Cho KH. Treatment of facial postinflammatory hyperpigmentation with facial acne in Asian patients using a Q-switched neodymium-doped yttrium aluminum garnet laser. Dermatol Surg 2010;36:1374-1380.

12. Wong Y, Lee SS, Goh CL. Hypopigmentation induced by frequent low-fluence, large-spot-size QS Nd:YAG laser treatments. Ann Dermatol 2015;27:751-755.

13. Grimes PE, Bhawan J, Kim J, Chiu M, Lask G. Laser resurfacing-induced hypopigmentation: histologic alterations and repigmentation with topical photochemotherapy. Dermatol Surg 2001;27:515-520.

14. Weismann K, Lorentzen HF. Dermoscopic color perspective. Arch Dermatol 2006;142:1250. 